\title{
PERANCANGAN SISTEM INFORMASI AKREDITASI PROGRAM STUDI SEKOLAH TINGGI TEKNOLOGI INDUSTRI (STTIND) PADANG
}

\author{
Veni Wedyawati ${ }^{1}$, Nofriadiman ${ }^{2}$ \\ 1,2 Program Studi Sistem Informasi Sekolah Tinggi Teknologi Industri (STTIND) Padang \\ Email : ${ }^{1}$ venywedya@yahoo.com, ${ }^{2}$ nofriadiman@yahoo.co.id
}

\begin{abstract}
Abstrak
Sekolah Tinggi Teknologi Industri (STTIND) Padang adalah salah satu instansi pendidikan berbentuk sekolah tinggi yang sudah menerapkan teknologi informasi baik sebagai pendukung aktifitas akademik maupun aktifitas pendukung non akademik lainnya. Untuk mendapatkan status akreditasi, diperlukan informasi mengenai Program Studi yang didapatkan dari pengisian instrumen penilaian akreditasi. Sistem pengarsipan akreditasi Program Studi STTIND Padang saat ini masih berbentuk manual. Data-data yang diperlukan untuk akreditasi masih tersimpan dalam berbagai sumber, sehingga untuk melakukan akreditasi harus mengumpulkan data-data tersebut yang membuat pihak kampus dan para Dosen kesulitan mencari data akreditasi ketika batas akreditasi hampir habis, data akreditasi tidak tersimpan dengan rapi, Program Studi sering kehilangan data pendukung akreditasi dalam bentuk lampiran, serta lamanya proses borang(akreditasi) pada STTIND Padang.

Untuk itu dalam penelitian ini dilakukan perancangan sistem informasi akreditasi Program Studi berbasis website yang khususnya untuk pengarsipan, dan MySQL sebagai media database.Dengan adanya Aplikasi webakreditasi membuat pekerjaan penyiapan bahan akreditasi oleh tim akreditasilebih efisien dari sistem yang sebelumnya. Aplikasi web akreditasi ini dapat membantu perguruan tinggi mendapatkan data arsip akreditasi sesuai yang diinginkan.
\end{abstract}

Kata kunci :Sistem Informasi, Pengarsipan, Akreditasi, MySQL dan Website

\section{PENDAHULUAN}

\subsection{Latar Belakang}

Pada masa di era globalisasi saat ini, perkembangan pengetahuan ilmu teknologi sangat pesat, apalagi saat sekarang ini sangat mudah mempelajari dan membuat program yang menarik dan berguna tanpa harus bekerja manual lagi. Status akreditasi merupakan cerminan kinerja sebuah Program Studi dalam menggambarkan mutu, efisiensi, serta relevansi suatu Untuk Program Studi di STTIND Padang pengelolaan akreditasi belum dilakukan dengan mengunakan sistem yang khusus untuk menangani data yang dibutuhkan dalam pengisian akreditasi.

Sistem pengarsipan akreditasi Program Studi STTIND Padang saat ini masih berbentuk manual. Data-data yang diperlukan untuk akreditasi masih tersimpan dalam berbagai sumber, sehingga untuk melakukan akreditasi harus mengumpulkan data-data tersebut yang membuat pihak kampus dan para Dosen kesulitan mencari data akreditasi ketika batas akreditasi hampir habis, data akreditasi tidak tersimpan dengan rapi,Program Studi sering kehilangan data pendukung akreditasi dalam bentuk lampiran, serta lamanya proses borang(akreditasi) pada STTIND Padang. Maka dari itu waktu yang digunakan untuk mengelola dan membaca dokumen-dokumen tersebut kurang efisien. Sejalan dengan perkembangan teknologi informasi dan komunikasi yang menawarkan kemudahan dan kecepatan dalam menyampaikan akses informasi untuk memenuhi kebutuhan dalam melakukan akreditasi lebih cepat dan mudah.

Untuk itu diperlukan suatu sistem informasi yang dapat mengelola dan menyimpan data borang akreditasi yang sekaligus dapat menjadi sarana untuk menampung serta menampilkan informasi mengenai Program Studi. Sistem tersebut juga bisa dijadikan template untuk menggambarkan kinerja Program Studi dan dapat dimanfaatkan oleh Program Studi yang lainnya. Tugas penulis akan membuat sistem informasi pengolahan akreditasi STTIND Padang berbasis Website. Penulis akan merancang suatu website yang memiliki tabel login 
dimana terdapat beberapa user dari pihak yang terkait dan dapat dilihat umum.

\subsection{Identifikasi Masalah}

1. Pengarsipan akreditasi STTIND Padang masih manual.

2. Program studi sering kehilangan data pendukung akreditasi dalam bentuk lampiran.

3. Data-data akreditasi tidak tersimpan dengan rapi.

\subsection{Batasan Masalah}

Permasalahan hanya akan merancang Sistem Informasi Akreditasi Program Studi di STTIND Padang yang khususnya dapat berfungsisebagai penyimpanan file borang akreditasi yang sekaligus dapat menjadi tempat untuk menampung informasi mengenai Program Studi.

\subsection{Rumusan Masalah}

1. Bagaimana cara membuat Aplikasi akreditasi STTIND Padang?

2. Bagaimana menciptakan kinerja yang efisien dengan pembuatan Aplikasi akreditasi STTIND Padang ?

\subsection{Tujuan Penelitian}

1. Membuat Aplikasi akreditasi STTIND Padang.

2. Menciptakan kinerja yang efisien dengan Aplikasi akreditasi STTIND Padang

\section{METODOLOGI PENELITIAN}

\subsection{JenisPenelitian}

Penulis menggunakan jenis penelitian terapan. Penelitian terapan yaitu penelitian yang diarahkan untuk mendapatkan informasi yang dapat digunakan untuk memecahkan masalah. Penelitian terapan dilakukan dengan tujuan menerapkan, menguji, dan mengevaluasi masalah-maslah praktis sehingga dapat dimanfaatkan untuk kepentingan manusia, baik secara individual maupun kelompok. Masalah penelitian terapan ditetapkan untuk mencari solusi yang dapat dimanfaatkan manusia. Penulis juga melakukan observasi langsung ketempat objek pokok permasalahan yang akan dibahas, yaitu pada bagian data-data arsip.

\subsection{Tempat dan Waktu Penelitian}

\subsubsection{Tempat Penelitian}

Penelitian dilakukan di STTIND

PADANG Pemilihan tempat ilakukan secara purposif (sengaja) dengan pertimbangan akan kelengkapan data dan informasi yang diperlukan untuk kegiatan penelitian mengenai pembuatan website sistem informasi pengarsipan akreditasi STTIND PADANG dengan menggunakan Dreamweaver 8.

\subsubsection{Waktu Penelitian}

Penelitian dilakukan pada bulan Januari 2017.

\subsection{VariabelPenelitian}

Variabel penelitian adalah segala sesuatu yang akan menjadi objek pengamatan dalam penelitian. Sesuai dengan permasalahan yang diteliti maka variabel penelitianmeliputi:

1. Data Standar 1, Sandar 2, Standar 3, Standar 4, Standar 5, Standar 6 dan Standar 7

2. Tata cara pengolahan data akreditasi di STTIND PADANG

\subsection{Data dan Sumber Data}

1. Data yang dibutuhkan

Data-data yang peneliti dibutuhkan dalam penelitian ini ada 2 yaitu :

a. Data Primer

Data primer adalah data yang didapat langsung di lapangan yaitu pada kampus STTIND Padang

b. Data Sekunder

Data sekunder diperoleh dari buku-buku literatur atau studi kepustakaan dan data-data dari perusahaan.

\section{Sumber Data}

Sumber data yang peneliti dapatkan berasal dari pengamatan danpendataan langsung padaSTTIND Padang.

\subsection{Langkah-Langkah Metoda Pene litian}

Untuk memperoleh data dan informasi dalam menyusun skripsi, maka diperlukan metode dalam pengumpulan data. Adapun metode pengumpulan data yang digunakan data yang digunakan penulis dalam memperoleh data yaitu :

1. Website pengarsipan akreditasi STTIND Padang.

Langkah-langkahnya sebagai berikut : 
a. Menyediakan semua data yang diperlukan untuk borang (akreditasi) STTIND Padang.

b. Menyediakan software untuk membangun sebuah website seperti Macromedia Dreamweaver8, xampp, tentunya mozila atau pun crome.

c. Macromedia dreamweaver 8 bertujuan untuk membangun atau merancang sebuah website seperti yang kita ingin kan.

d. Setelah merancang website perlu kita gunakan pula media server gratis seperti xampp. Disini xampp berguna untuk melihat apakah website yang kita bangun tersebut berhasil atau tidak, tetapi xampp tidak akan berguna kalau tidak ada mozila ataupun crome karena mozila sebagai media penghubung internet.

e. Setelah website itu telah jadi baru lah kita input kan semua data yang ada.

2. Menciptakan kinerja yang efisien dengan Aplikasi akreditasi STTIND Padang yaitu dengan cara browser atau dijalankan dengan Mozilla atau Crome.

\section{HASIL DAN PEMBAHASAN}

\subsection{Analisa Sistem}

Dalam Perancangan Sistem Informasi perlu terlebih dahulu dilakukan analisa sistem terhadap sistem yang sedang berjalan. Dalam melakukan analisa sistem diperlukan data-data yang telah ada pada sistem yang lama. Data yang diperlukan merupakan hal-hal yang berkaitan dengan akreditasi. Penelitian terhadap beberapa kelemahan sistem dari segi kecepatan dan efisien sistem yang ada atau yang sedang digunakan.

Tahapan analisa yang dilakukan adalah memahami sejauh apa kinerja sistem informasi akreditasi Program Studi yang sedang berjalan, mengidentifikasi permasalahan pada sistem yang ada, kelemahan dan hambatan yang ditemukan, kebutuhan yang diharapkan kemudian menarik kesimpulan dari proses analisa yang telah dilakukan.

\subsubsection{Evaluasi Sistem Yang Sedang Berjalan}

Evaluasi sistem yang sedang berjalan pada Sistem akreditasi STTIND Padang yaitu sesuai hasilpengamatan dan penelitian yang dilakukan pada sistem pengolahan data masih terkendala pada sistem yang masih dilakukan secara manual, tidak adanya aplikasi atau penyimpanan khusus untuk arsip akreditasi STTIND Padang, sehingga pihak kampus dan para Dosen mencari data akreditasi ketika batas akreditasi hampir habis.

\subsubsection{Us ulan Sistem Baru}

Dari kendala tersebut maka dapat dilakukan pengembangan terhadap sistem sehingga menjadi sistem yang baru dan kendala yang dihadapi dapat teratasi yaitu dengan melakukan :

1. Pembuatan website akreditasi STTIND Padang

2. Pembuatan interface dengan menggunakan bahasa pemrograman berbasis PHP MySQL

\subsection{Desain Sistem}

Desain Sistem adalah tahap setelah analisis sistem dari siklus pengembangan system yang mendefinisikan dari kebutuhankebutuhan fungsional ,persiapan untuk rancang bangun implementasi, menggambarkan bagaimana suatu system dibentuk yang dapat berupa penggambaran, perencanaan dan pembuatan sketsa atau pengaturan dari beberapa elemen yang terpisah kedalam satu kesatuan yang utuh dan berfungsi, termasuk menyangkut mengkonfigurai dari komponen-komponen perangkat lunak dan perangkat keras dari suatu system.

\subsubsection{Use Case Diagram}

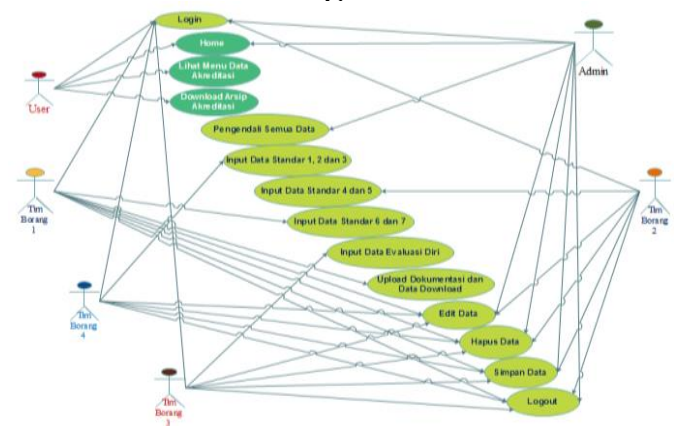

Gambar 3.1 Use Case Diagram 


\subsubsection{Class Diagram}

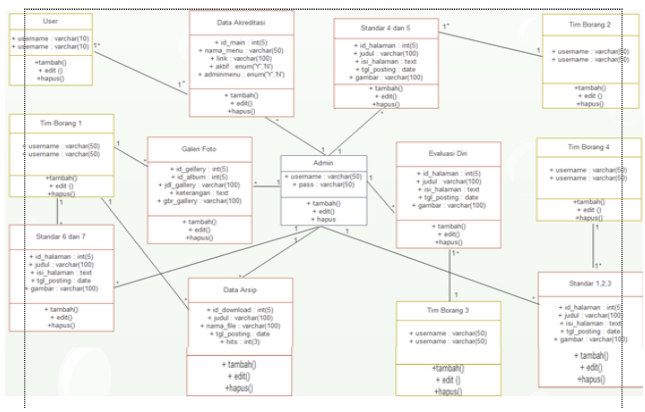

Gambar 3.2 Class Diagram

\subsubsection{Sequence Diagram}

a. Sequence Diagram User

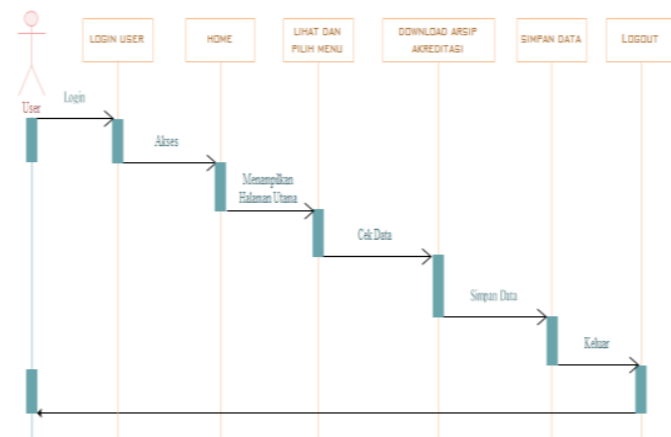

Gambar 3.3 Sequence Diagram User

b. Sequence Diagram Admin

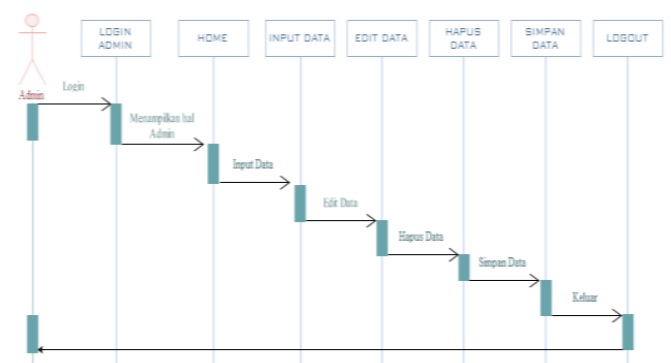

Gambar 3.5 Sequence Diagram Admin c. Sequence Diagram Tim Borang 1

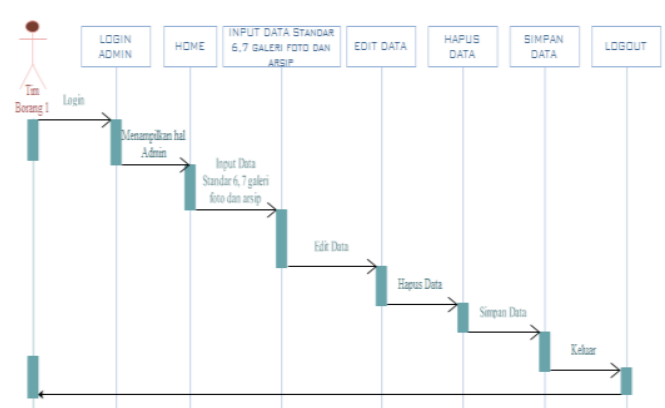

Gambar 3.6 Sequence Diagram Tim B orang 1

d. Sequence Diagram Tim Borang 2

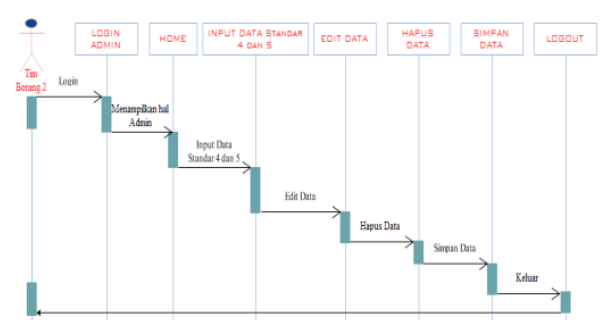

Gambar 3.7 Sequence Diagram Tim Borang 2

e. Sequence Diagram Tim Borang 3

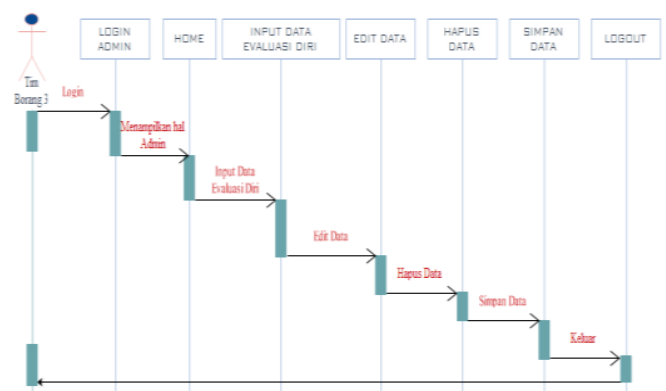

Gambar 3.8 Sequence Diagram Tim B orang 3 
f. Sequence Diagram Tim Borang 4

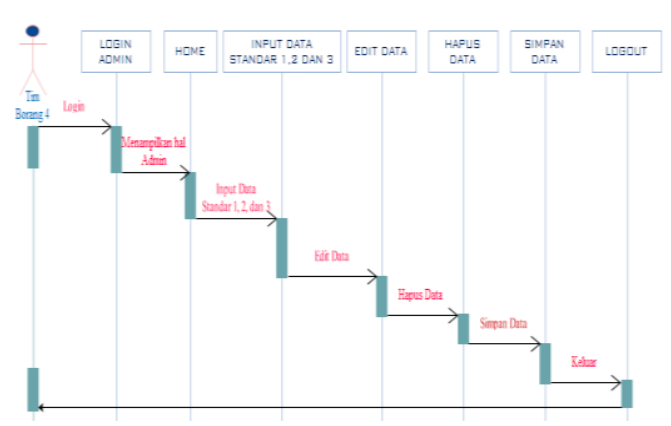

Gambar 3.9 Sequence Diagram Tim Borang 4

\subsubsection{Activity Diagram}

Activity Diagram User

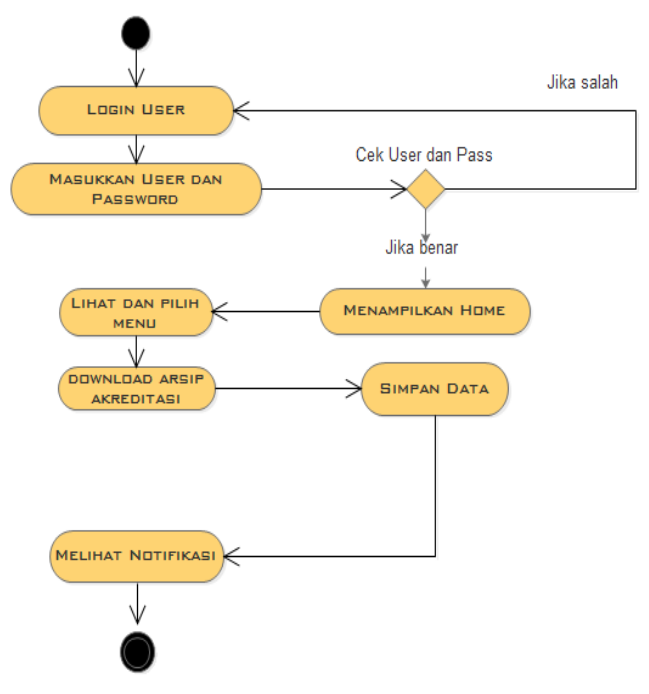

Gambar 3.10 Activity Diagram User
Activity Diagram Admin

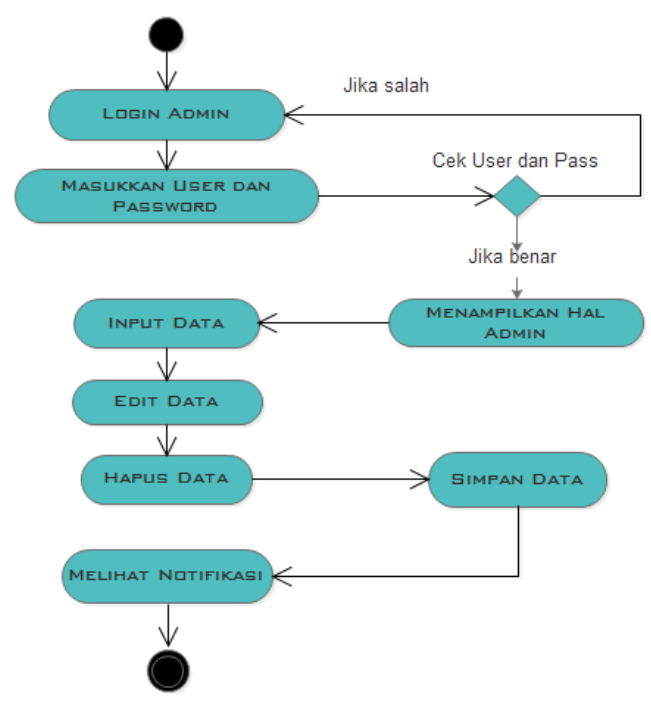

Gambar 3.11 Activity Diagram Admin Activity Tim Borang 1

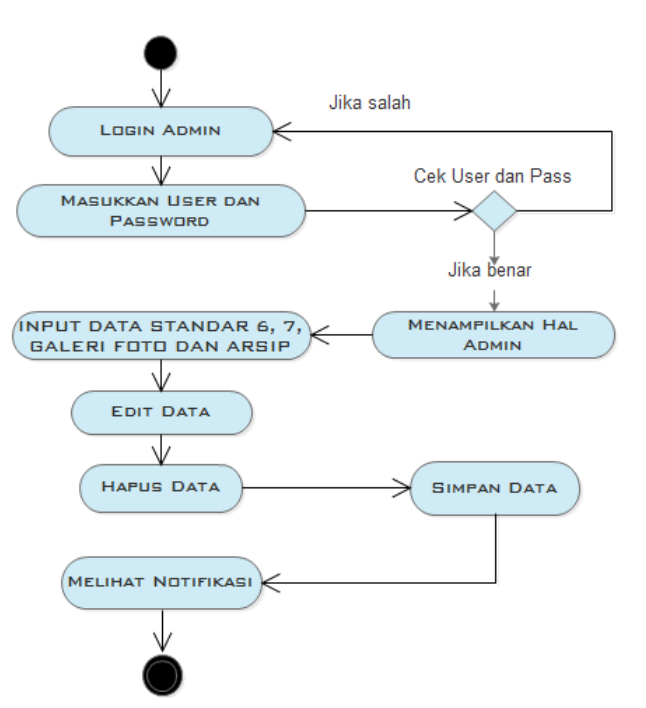

Gambar 3.12 Activity Diagram Tim Borang 
Activity Tim Borang 2

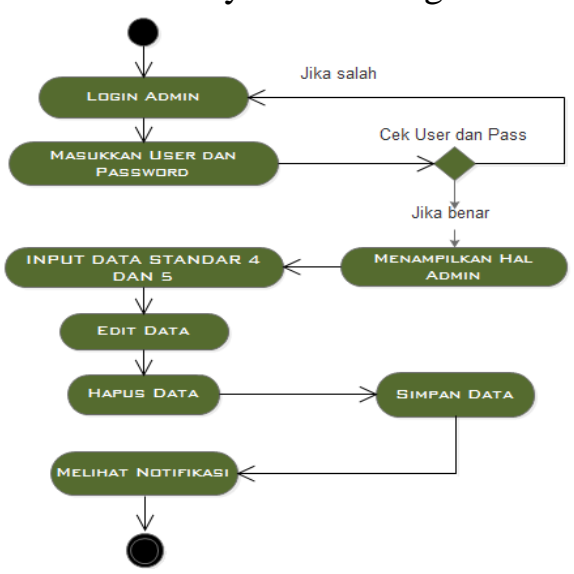

Gambar 3.13 Activity Diagram Tim Borang 2

Activity Tim Borang 3

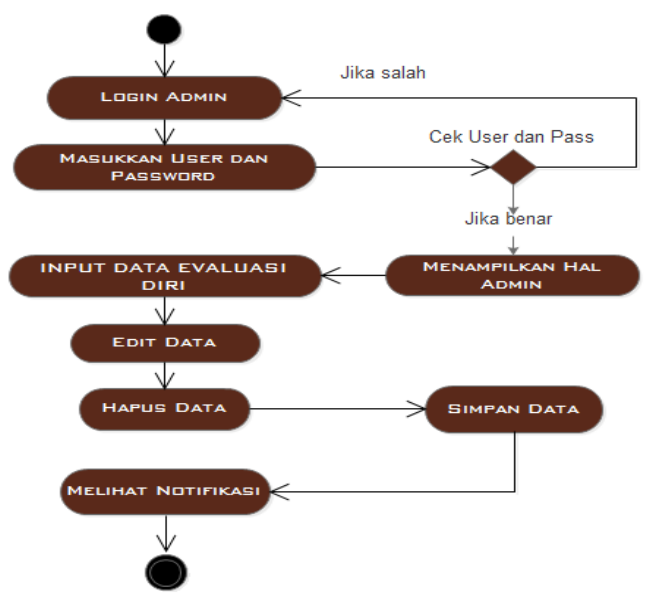

Gambar 3.14 Activity Diagram Tim Borang 3

Activity Tim Borang 4

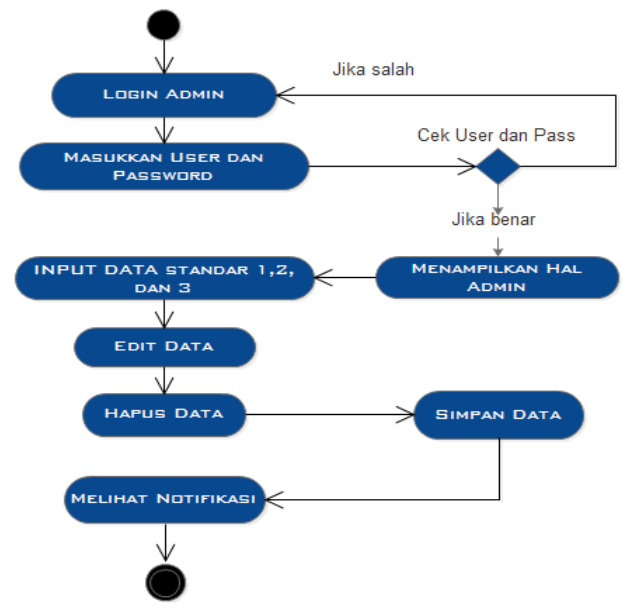

Gambar 3.15 Activity Diagram Tim Borang

4

\section{IMPLEMENTASI SISTEM}

\subsubsection{Login User}

Sebelum user masuk ke website, user harus login terlebih dahulu. Berikut tampilan form login user :

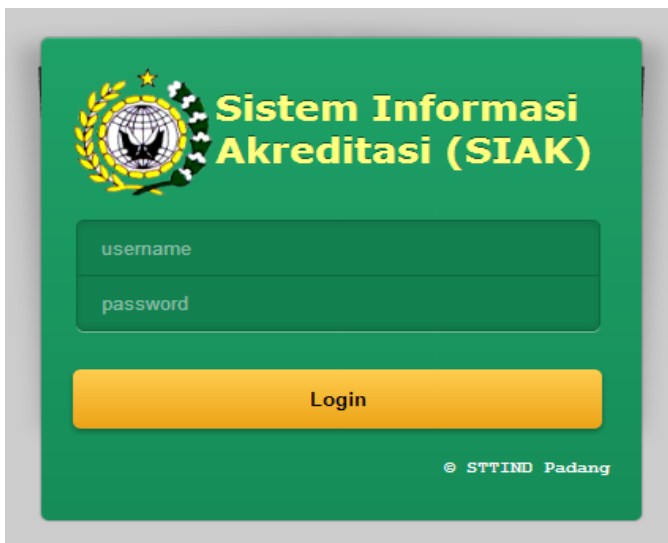

Gambar 4.1 Tampilan Login User

\subsubsection{Halaman Home user}

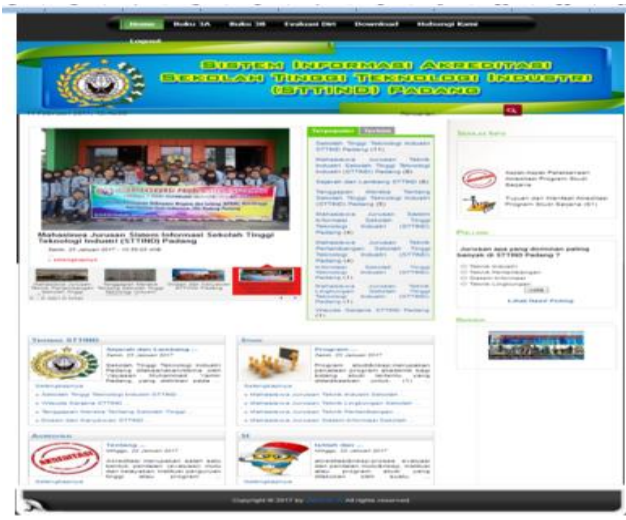

Gambar 4.2 Tampilan Home User 


\subsubsection{Buku 3A}

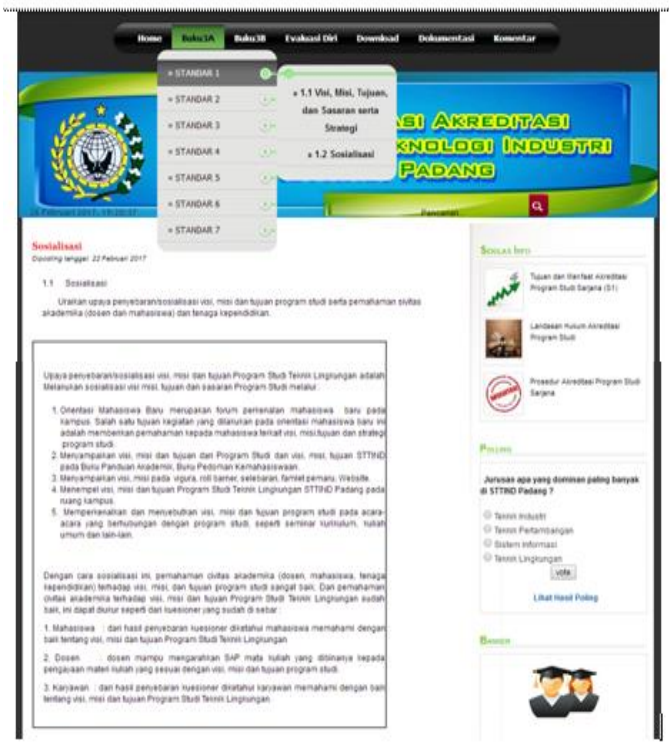

Gambar 4.3 Tampilan Buku 3A

\subsubsection{Evaluasi Diri}

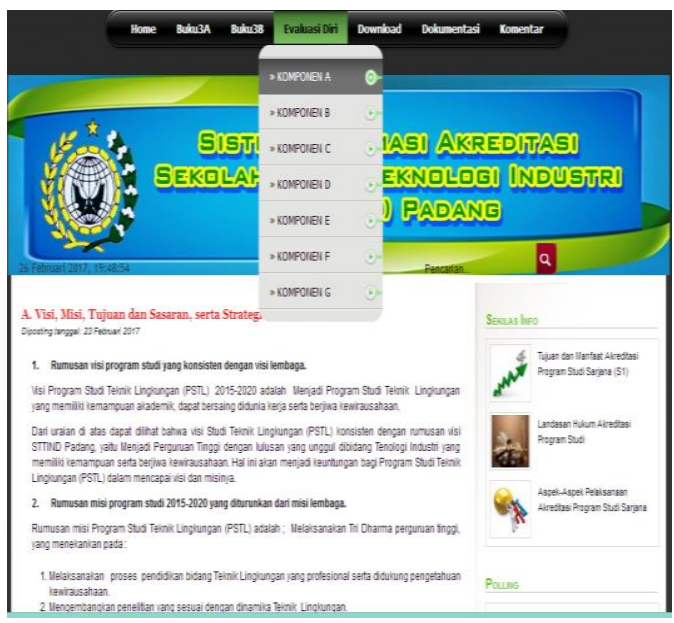

Gambar 4.4 Tampilan Evaluasi Diri

\subsubsection{Download}

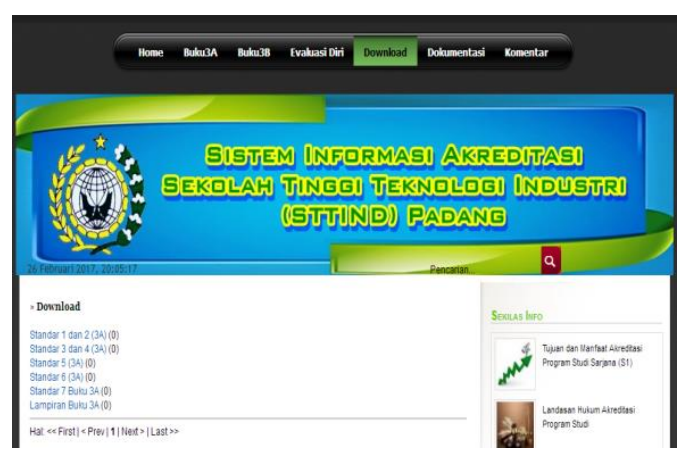

Gambar 4.5 Tampilan Download

\subsubsection{Dokumentasi}

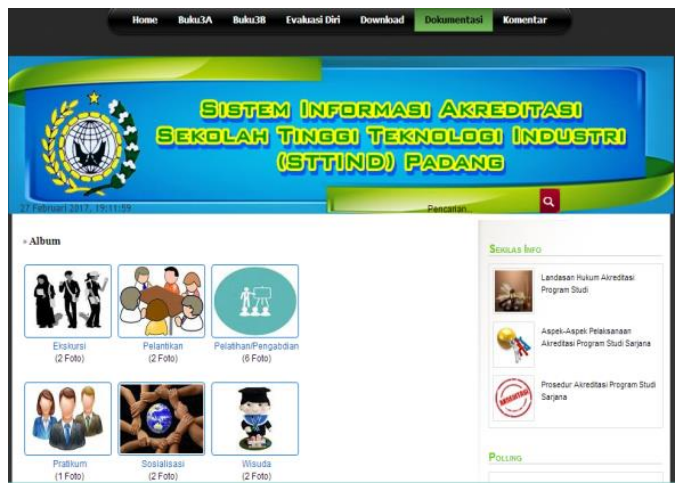

Gambar 4.6 Tampilan Dokumentasi

\subsubsection{Komentar}

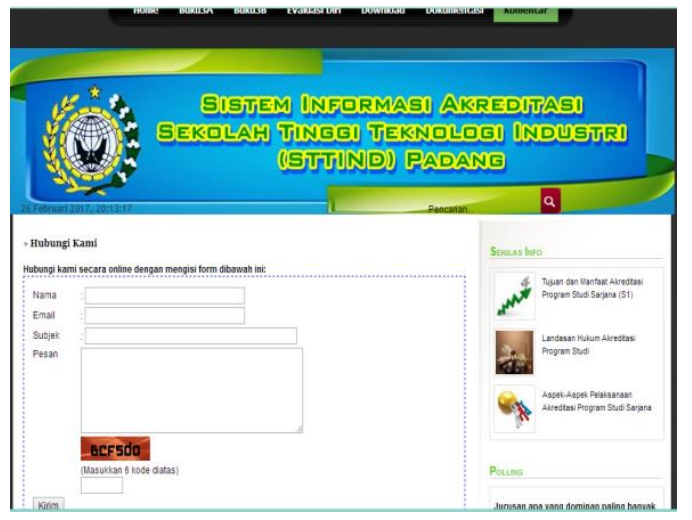

Gambar 4.7 Tampilan Komentar

\subsubsection{Login Admin}

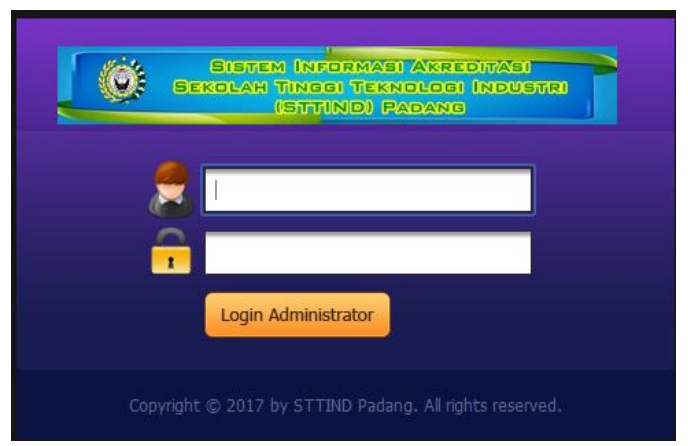

Gambar 4.8 Tampilan Login Admin 


\subsubsection{Menu Home Admin}

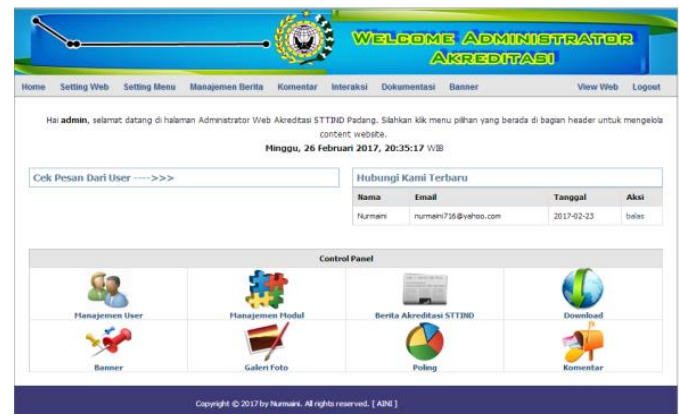

Gambar 4.9 Tampilan Home Admin

\section{KESIMPULANDAN SARAN}

\subsection{Kesimpulan}

Dari hasil perancangan sistem yang telah dilakukan, maka penulis dapat mengambil kesimpulan sebagai berikut :

1. Sistem Informasi Akreditasi pada Program Studi BerbasisWeb dibuat dengan untuk mempermudah proses penyimpanan data-data akreditasi.

2. Dengan adanya Aplikasi webakreditasi Perguruan Tinggi membuat pekerjaan penyiapan bahan akreditasi oleh tim akreditasilebih efisien dari sistem yang sebelumnya. Akreditasi Program Studi dimaksudkan untuk dijadikan sebagai bahan evaluasi, agar program studi melakukan perbaikan - perbaikan kinerja untuk mengoptimalisasikan standar mutu pendidikan, serta Aplikasi web akreditasi ini dapat membantu perguruan tinggi mendapatkan arsip akreditasi sesuai harapan.

\subsection{Saran} yaitu :

Adapun saran yang dapat saya berikan

1. Sistem dapat dikembangkan dengan menambahkan fitur mencetak dokumen untuk setiap starndar sesuai dengan format dokumen borang akreditasi program studi yang telah ditentukan.

2. Aplikasi akreditasi yang dibuat ini, masih sangat sederhana darisegi tampilan, dan masih banyak kegiatan yang belum ditampilkan sepertilaporan SPMI, rencana strategis, statuta dll. Untukitu, perlu dikembangkan dan pembaharuan informasi baik isi maupun tampilan.

\section{DAFTAR KEPUSTAKAAN}

Firdaus. PHP dan MySQL dengan Maromedia Dreamwaver 8. Jakarta: 2007

Hariyanto, Bambang. Dasar Informatika dan Ilmu Komputer.Yogyakarta: Graha Ilmu. 2008

Hartama, Dedy. Pemrograman Web Dengan HTML, CSS, Javascript.Yogyakarta: Andi.2012

Http://library.binus.ac.id/eColls/eThesisdoc/B ab2/2012-2-00081 MNSI\%20Bab2001.pdf Janner Simarmata. Perancangan Basis Data. Yogyakarta: Penerbit Andi. 2007 